\title{
DISCUSSION
}

\section{Behaviour of jacked and driven piles in sandy soil}

\author{
J. YANG, L. G. THAM, P. K. K. LEE, S. T. CHAN and F. YU (2006). Géotechnique 56, No. 4, $245-259$
}

\section{B. H. Fellenius, Calgary, Canada}

The discusser questions the authors' method of determining the distribution of unit shaft resistance from the distribution of measured loads in the piles. The authors calculated the unit shaft resistance from the change of load between the strain-gauge levels divided by the lengths between the gauge levels and the circumferential area of the pile. Such differentiation will invariably enlarge data imprecision. For example, the load in the pile diminishes on average about $8 \%$ from one gauge location to the next. Assuming, realistically, that the measurement imprecision (error) in each load value is about $\pm 4 \%$ of the value, then, as opposed to a case where the loads are infinitely precise, the potential error in the evaluated unit shaft resistance determined by differentiation between the two gauge levels will range from zero to twice the correct value. The discusser believes the erratic distributions of unit shaft resistance illustrated in Figs 10 and 11 are due not to variation of the unit shaft resistance, but to imprecision of the strain measurements (and their conversion to stress or load) in the piles. A more realistic distribution of the unit shaft resistance can be obtained by first fitting the measured load distributions to an effective stress analysis, which results in a smoothed distribution curve, a filtering of the errors. The unit shaft resistance can then be determined from the arithmetic relations of the so-filtered distribution of load in the pile.

The discusser has fitted the data points in Figs 8 and 9 to an effective stress analysis assuming hydrostatic pore pressure distribution, shear forces developing on the surface of the ' $\mathrm{H}$ ' rather than on the square box around the ' $\mathrm{H}$ ', and, for this analysis, employs the authors' zeroing of the gauges before the test. Figs 23 and 24 show the so-fitted load distributions together with the data of Figs 8 and 9 (after conversion from pile stress to pile load). The distributions shown are those for the maximum loads applied in the static loading tests on the piles. The fit is good for piles PJ1, PJ8 and PD2, but less so for pile PD8. However, the authors' load distribution for pile PD8 (Fig. 9(b)), indicating no shaft resistance between the depths of $4 \mathrm{~m}$ and $30 \mathrm{~m}$, is not believable. It is probable that the gauges have malfunctioned, supplying data with larger scatter and errors than shown by the gauges in the other three piles. Therefore the discusser has chosen to use the same effective stress distribution for pile PD8 as for pile PD2. Each graph lists the effective stress proportionality coefficients, the $\beta$-coefficients, used for the particular fitting, taken as an approximately constant value within the two soil layers identified by the borings.

The unit shaft resistance values determined from the effective stress calculation fitted to the measured load distributions are plotted in Figs 25 and 26 together with the distributions of Figs 10 and 11 respectively. In the discusser's opinion, the calculated straight-line distributions are more representative for the unit shaft resistance distributions than the authors' differentiation approach. With regard to pile D8, the authors' four values of negative shaft resistance per the differentiation approach further emphasise that the gauge readings from pile PD8 cannot be correct.

The beta coefficients determined from the jacked piles are larger than those of the driven piles, seemingly agreeing with the authors' conclusion that larger shaft resistance was obtained for the jacked piles than for the driven piles. However, in the discusser's opinion, this conclusion is not necessarily correct.

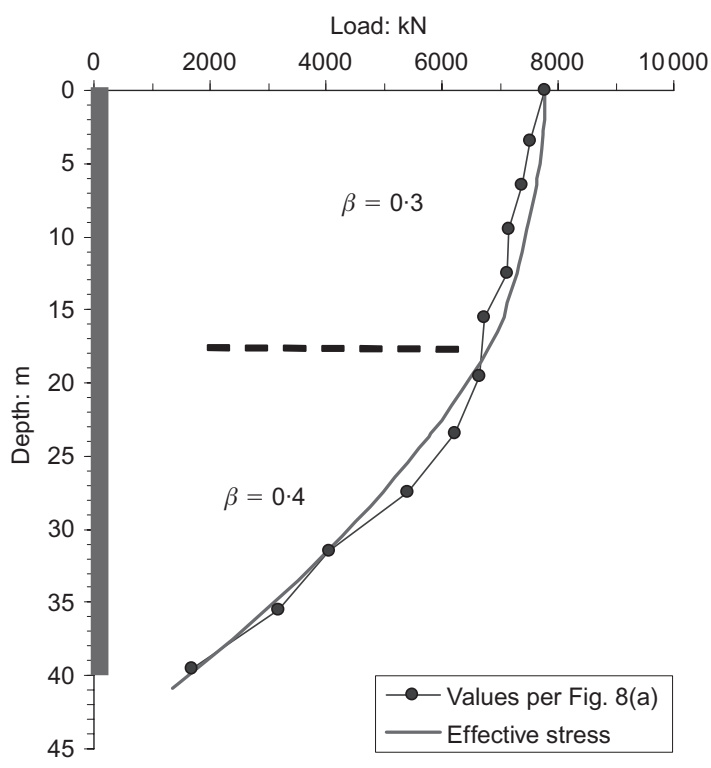

(a)

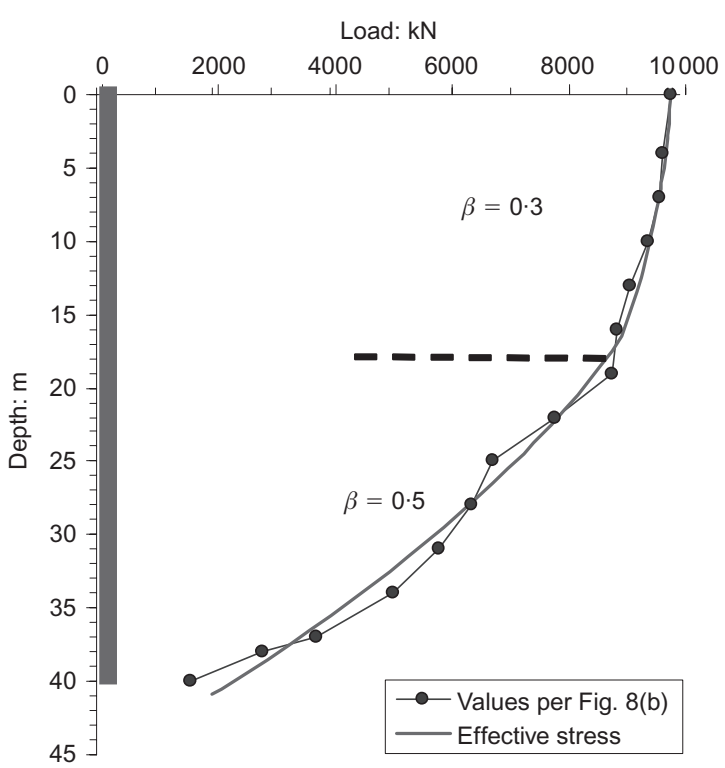

(b)

Fig. 23. Load distributions for (a) pile PJ1 and (b) pile PJ8 from data points shown in Figs 8(a) and 8(b), converted from axial stress to load and approximated in an effective stress analysis employing the beta coefficients shown. 


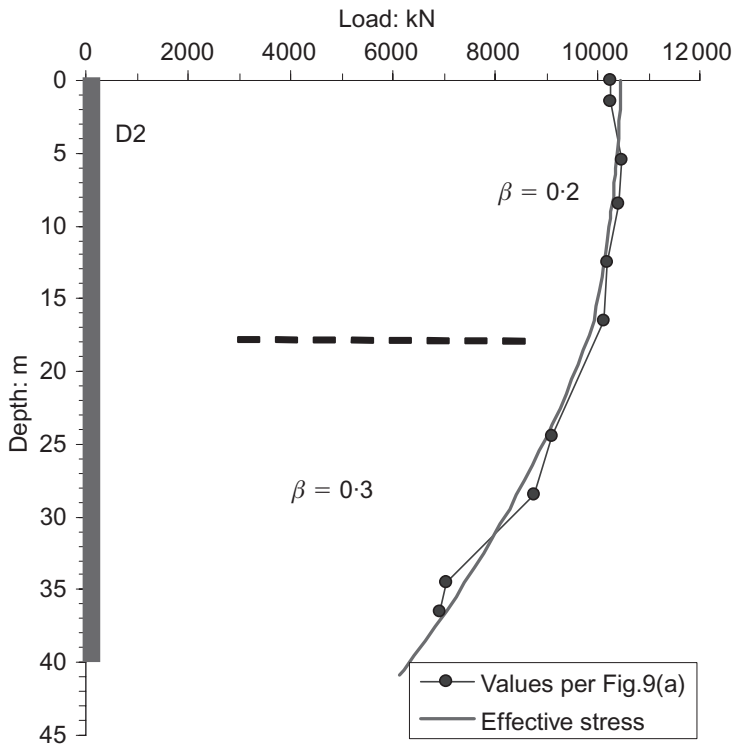

(a)

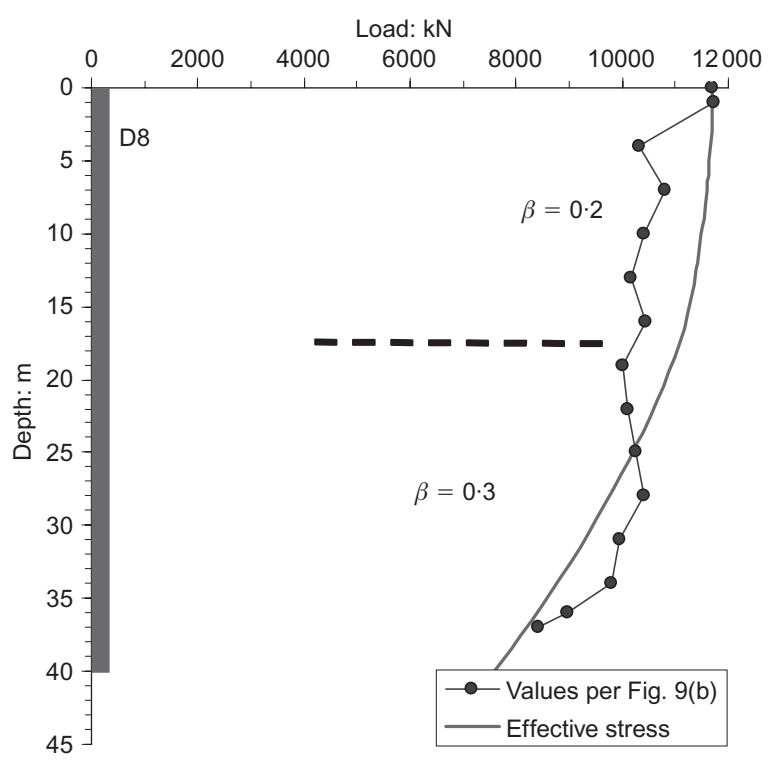

(b)

Fig. 24. Load distributions for (a) pile PD1 and (b) pile PD8 from data points shown in Figs 9(a) and 9(b), converted from axial stress to load and approximated in an effective stress analysis employing the beta coefficients shown.

The authors have-stating this to be intentional-disregarded the effect of residual load (locked-in load) in the piles at the start of the static loading tests. This is surprising, given that the gauges were present in the pile during the installation of the piles and were available for taking readings before the start of the static loading tests. For the jacked piles, in particular, the load remaining in the pile after unloading surely must have indicated that loads were locked in as a result of the jacking. Gauge readings before the start of the tests would have established the residual load distribution in the pile. Moreover, the fact that the testing of five of the nine driven piles showed a 'negative settlement' after unloading is a direct indication of the presence of residual load. (When in the loading test, the pile toe is not moved appreciably, and the shaft resistance is degraded somewhat by the test, a portion of the residual load is unloaded, which results in a corresponding elongation of the pile and a higher elevation of the pile head after the test in relation to the before-the-test elevation.)

When omitted from the analysis, the presence of residual load will cause the evaluation of the gauge data to show the shaft resistance to be larger than the true value. Where the residual load is fully developed, the so-evaluated shaft resistance will be twice the true shaft resistance. Moreover, the evaluation will result in an underestimated magnitude of the pile toe resistance. Finally, the pile-head load-movement curve will appear stiffer for a pile with larger residual load than for a pile with smaller.

It is possible, indeed probable, that the residual loads in the driven piles will be smaller than in the jacked piles. If so, the omission of the presence of residual load will result in the evaluated shaft resistances being larger for the jacked piles than for the driven piles, even if the ultimate unit shaft resistance would be the same whether the piles were jacked or driven. Indeed, as the authors excluded the residual load in their analysis, the difference shown by the authors is not likely to be true.

The toe resistance is of course a function of how hard the piles were driven. The case indicates that the driven piles were probably installed to a somewhat larger toe resistance than the jacked piles were: this despite the fact that the authors' analysis is likely to have shown a toe resistance smaller than the true value because of the omission of the locked-in toe loads.

In the discusser's opinion, the conclusion that the jacked piles develop more shaft resistance than the driven piles is not supported by the authors' data. Whether or not there is a difference is unknown, because the residual loads are omitted from the authors' analysis. It is also the discusser's opinion that other conclusions of the authors are not valid, inasmuch as they are based on the apparent differences of shaft resistance and pile stiffness originating in the omission of gauge errors and residual loads.

\section{Authors' reply}

The discusser raises two points in his discussion. The first concerns the method of determining the distribution of unit shaft resistance. As indicated in the paper, the unit shaft resistance for any section between two gauge levels was determined as the difference of the pile loads at the two levels divided by the surface area of the pile section. The unit shaft resistance should thus be regarded as an average value for the section, and the plotted shaft resistance distribution should be treated as an approximate rather than an exact representation. This is a widely used practice in Hong Kong, and is also, to our best knowledge, common practice in many other regions outside Hong Kong. We consider the discusser's method one of the alternatives for shaft resistance interpretation that may help in viewing the test results in a different way. We do not agree, however, with the discusser's opinion that the method is superior over the common practice in that it is able to provide 'a more realistic' distribution of shaft resistance.

The discusser's method assumes that the distribution of shaft resistance is perfectly linear with a constant beta value, which should be an idealised rather than a real case, as natural deposits are never perfectly uniform. Lehane et al. (1993) conducted a load test on an instrumented model pile at a sand deposit that was considered highly uniform. The local shear stress (i.e. shaft resistance) was measured directly from stress transducers at three different distances $(h)$ from the tip of the pile as it was jacked into the ground. Shown in Fig. 27 are profiles of the local shear stress (where $R$ is pile radius), which clearly indicate the phenomenon of friction degradation at a given depth. Lehane et al. state that 


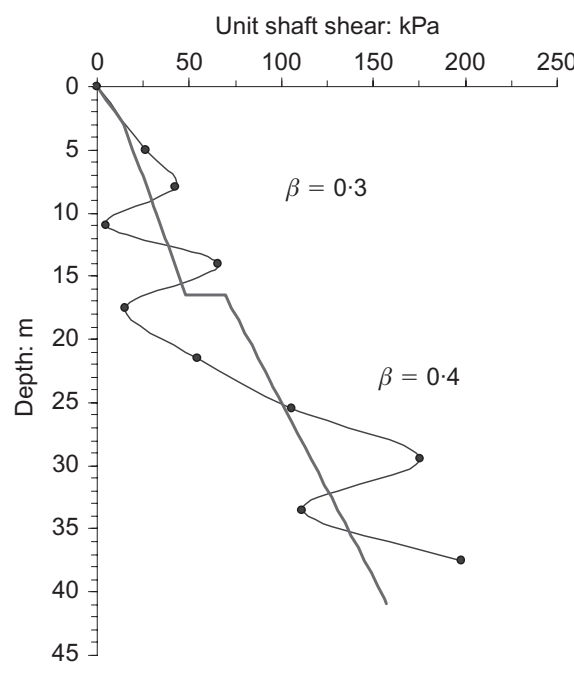

(a)

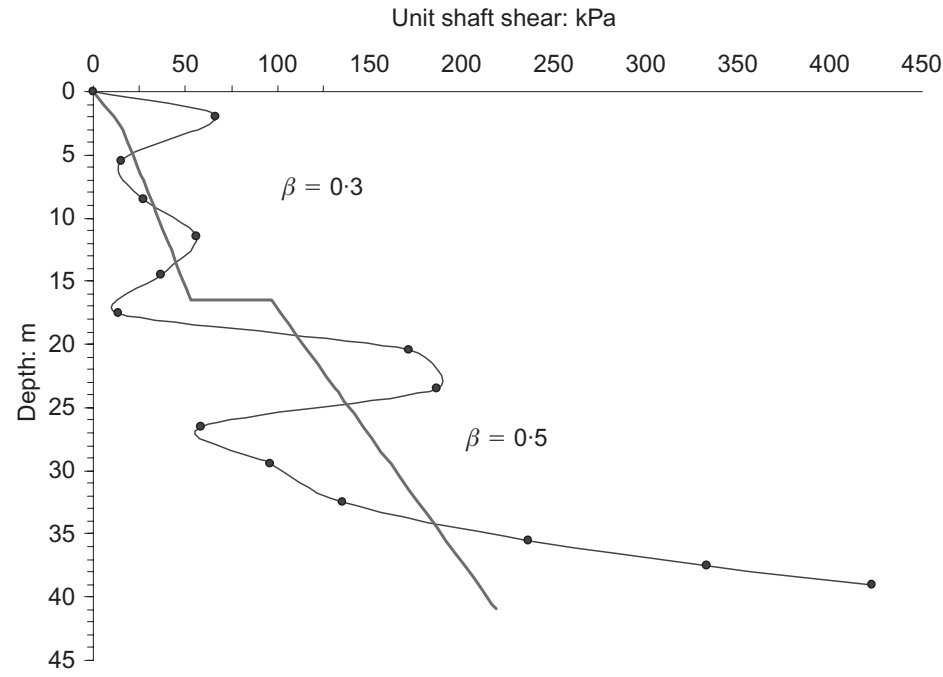

(b)

Fig. 25. Distribution of unit shaft resistance from the effective stress analysis and the distributions presented in Fig. 10: (a) pile PJ1; (b) pile PJ8

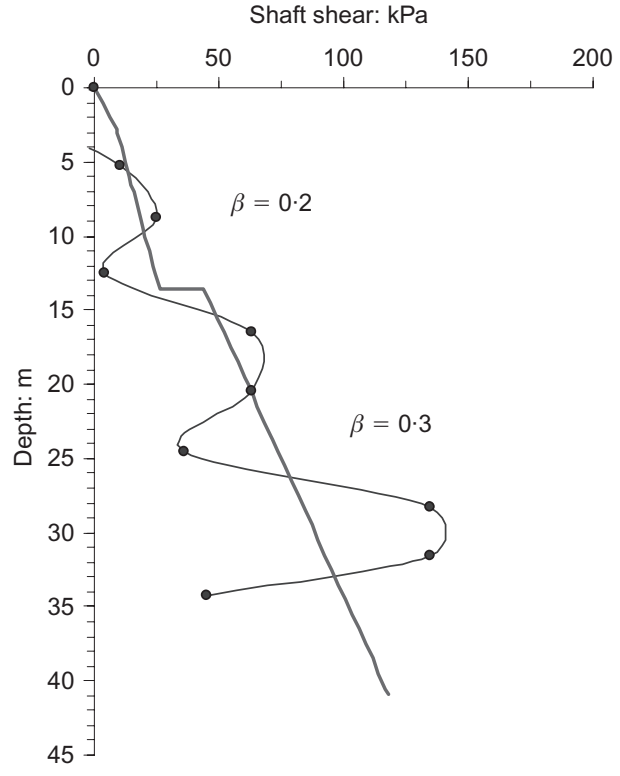

(a)

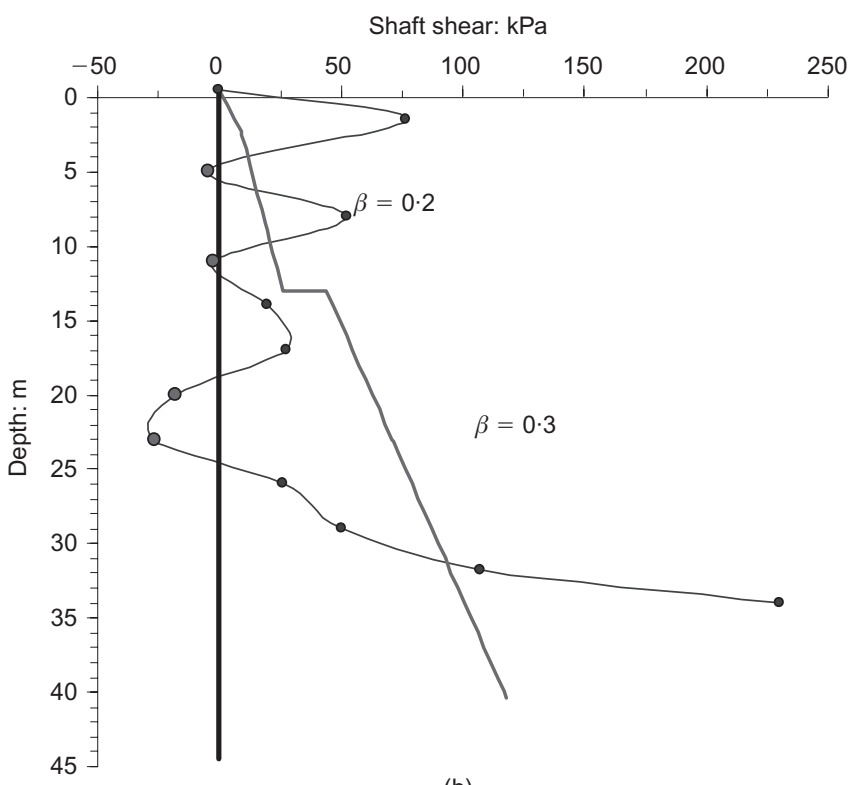

(b)

Fig. 26. Distribution of unit shaft resistance from the effective stress analysis and the distributions presented in Fig. 11: (a) pile PD2; (b) pile PD8

the reduction in stress with increasing pile penetration provides a rational explanation for the concept of critical depth, a much debated issue in the area of pile foundations over past decades. The friction degradation is considered to be connected with the cyclic loading action of the surrounding soil during pile installation. This fatigue mechanism also provides a good explanation for the difference in shaft friction between jacked and driven piles observed in Fig. 18 in our paper.

The above example highlights the complexity of the problem we are dealing with. In this regard, as stated in the original paper, while we consider that some anomalous values of shaft resistance (for PD8) may be due to rogue gauge measurements, we also recognise that there exist other potential reasons. These potential reasons may include, for example, the existence of soft layers that were not discovered by the limited number of boreholes at the site, or the existence of a gap between the pile and the surrounding soil due to pile installation. It has frequently been observed that, when an H-pile penetrates into the ground, whether by driving or jacking, the overlying soil may be dragged down by the pile to lower levels, leaving a gap between the pile and the soil at the upper levels. This phenomenon was also reported by, for example, Tomlinson (1977) and Poulos \& Davies (1980). Fitting of the pile-load curve using a smooth curve will simply remove the clue for these real-life variations.

The second point raised by the discusser concerns the residual stress effect on pile load tests. The existence of locked-in load in a pile after installation has been known for a long time (Nordlund, 1963; Gregersen et al., 1973). However, it is not easy to demonstrate, and it is even more difficult to quantify the effect on test data, because the conditions for shift of the gauge reading before the start of 


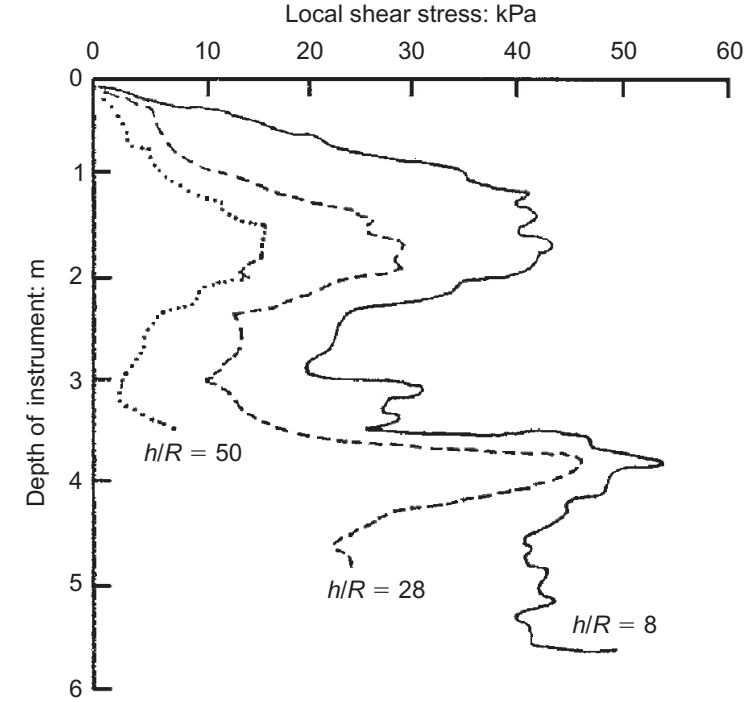

Fig. 27. Measured profiles of shaft friction (Lehane et al., 1993)

load test are complicated, and influenced by many details of pile installation (e.g. placing the pile in the lead before installation, and splicing pile segments during installation). It has thus been common practice to zero the gauges before the start of a pile load test. Very few evaluations of residual stress, as pointed out by Van Impe (1994), have been presented in the literature. In a prediction symposium that was held by the ASCE Geotechnical Engineering Division in conjunction with the 1989 Foundation Engineering Congress, the results of load tests on four instrumented piles were used as the basis for prediction (Finno, 1989). Of the 23 people who made predictions, only three chose to predict the residual loads induced by piledriving. This small number of predictions for residual loads emphasises the difficulties associated with residual load interpretations.

One particular difficulty or uncertainty in the evaluation of the residual load effect, in our opinion, comes from the impact of adjacent pile installation. Yang et al. (2006) show that both the magnitude and the distribution of the stress in an existing pile are largely influenced by nearby pile driving, as shown in Fig. 28, where the profiles of axial stress in pile PJ2 induced by jacking of a nearby pile (PJ5) are given. Note that significant tensile stresses dominating in the major portion of PJ2 were measured, which may substantially reduce the locked-in stresses (mainly in compression) due to the installation of PJ2 itself. Therefore, in order to have meaningful interpretations, both the testing programme and the piling programme need to be well managed, which, given the time and economics in most practical projects, would not be easy to achieve. In our field study we have made an effort to investigate the residual load effect for pile PJ2 by using strain measurements in different phases. A preliminary analysis (Yang \& Sze, 2005) indicates that the existing methods do not give a satisfactory prediction of the residual
Pile stress: $\mathrm{MPa}$

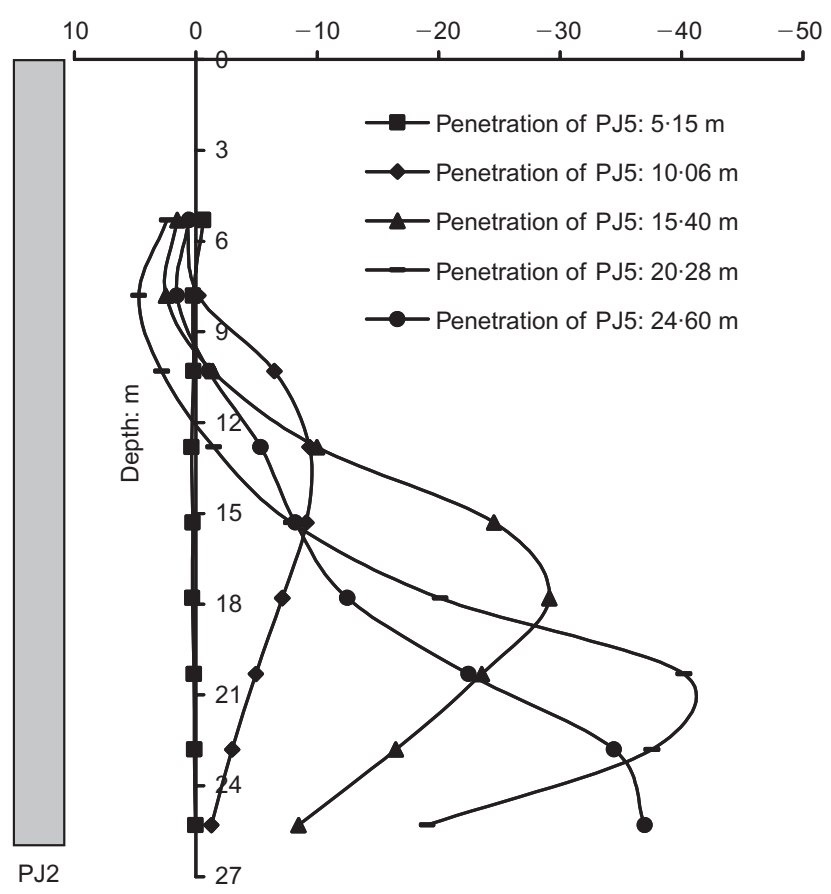

Fig. 28. Measured profiles of axial stress in PJ2 induced by jacking of PJ5 (Yang et al., 2006)

loads. Detailed data interpretations are in progress, and will be reported in future papers.

In summary, the residual load effect remains a very tricky and difficult issue, and current practice is considered acceptable. In this regard, we agree with Van Impe (1994) that we should not 'overestimate the possibilities of predicting residual loads, since they are too sensitive to the pile installation procedure and pile group effects, usually rendering its prediction errors above all acceptable levels'.

\section{REFERENCES}

Finno, R. J. (ed.) (1989). Predicted and observed axial behavior of piles. Geotech. Special Pub. No. 23, ASCE.

Gregersen, O. S., Aas, G. \& Dibagio, E. (1973). Load tests on friction piles in loose sand. Proc. 8th Int. Conf. Soil Mech. Found. Engng, Moscow 2, 109-117.

Nordlund, R. L. (1963). Bearing capacity of piles in cohesionless soils. J. Soil Mech. Found. Engng ASCE 89, No. SM3, 1-35.

Poulos, H. G. \& Davis, E. H. (1980). Pile foundation analysis and design. New York: John Wiley \& Sons.

Tomlinson, M. J. (1977). Pile design and construction practice. London: Viewpoint Publications.

Van Impe, W. F. (1994). Developments in pile design. Proc. 4th Int. DFI Conf., Balkema, Rotterdam, 727-758.

Yang, J. \& Sze, H. Y. (2005). Estimation of bearing capacity of displacement piles in sandy soil. Report, Department of Civil Engineering, University of Hong Kong. 